\title{
Families and Innovative Consumer Behavior: A Triadic Analysis of Sibling and Parental Influence
}

\author{
JUNE COTTE \\ STACY L. WOOD*
}

\begin{abstract}
Although family socialization is a rich field in consumer behavior, to date no research has been done to disaggregate family influences on behavior into separate parent and sibling components. Here we use triadic analysis (parent and two siblings) to explore the influence of family on consumer innovativeness. We develop hypotheses that postulate parental influence, and, based on conflicting views of sibling similarity in the recent behavioral genetics and developmental psychology literature, set competing hypotheses about sibling influence on innovativeness and innovative behavior. Using a model tested with triads from 137 families, we find that both parents and siblings influence innovativeness, but that parental influence is stronger than sibling influence. We discuss the implications of our work for the study of family influence in consumer behavior.
\end{abstract}

\begin{abstract}
A family exerts a complex influence on the behaviors of its members. Prior family influence research has focused on intergenerational rather than intragenerational influence in consumer socialization. As has been compellingly demonstrated, parents influence children (Moore, Wilkie, and Lutz 2002; Moschis 1987). Yet, consumption domains clearly exist where sibling influence may also be exerted. The nature of this influence, however, is a matter of some debate. A consideration of recent research in behavioral genetics and developmental psychology leads to two conflicting pictures of sibling effects. In this research, we test these effects in one consumption domain, consumer innovativeness, that has the potential for both parental and sibling influence.

Consumers are increasingly faced with new products and new channels of purchase. Much research in the consumer literature explores the mechanisms by which consumers change or respond to innovations, both at macro- or marketlevel perspectives (Rogers 1995) and micro- or consumerlevel perspectives (e.g., Moreau, Lehmann, and Markman 2001; Wood and Lynch 2002). Given the level of resources necessary for new product development and introduction,

*June Cotte is assistant professor of marketing, Ivey Business School, University of Western Ontario, London, ON, Canada, N6A 3K7 (jcotte@ ivey.ca). Stacy L. Wood is assistant professor of marketing, Moore School of Business, University of South Carolina, Columbia, SC 29208 (wood@ moore.sc.edu).The authors thank the editors and three reviewers for their comments, and thank Terry Shimp, Niraj Dawar, Robert Fisher, Don Barclay, Jim Gentry, and Ratti Ratneshwar for their feedback on earlier versions of this article. They also gratefully acknowledge research funding from the University of South Carolina Office of Sponsored Programs and Research.
\end{abstract}

marketers are clearly very interested in what makes consumers likely to try something new. We suggest that family influence may be one important indicator of adoption probability.

In this research we develop and empirically test a model of family influence on innovativeness. Thus, our contribution is twofold. First, we seek to add to current knowledge on consumer response to new product innovations by demonstrating both intergenerational and intragenerational family influence. Second, we build on the extant family influence literature by providing an example of a domain where it is theoretically useful to consider jointly the impact of both sibling and parental influence.

This article uses triadic analysis (parent and two siblings) to explore the influence of family on consumer innovativeness. Family socialization influences are usually conceptualized and tested as a dyadic (husband-wife or parent-child) phenomenon. Our research is, to the best of our knowledge, the first to simultaneously study two main components of family influence: the influence due to parents and the influence due to a sibling. Thus, our study answers Roedder John's (1999) call for research that disaggregates overall family influence; it continues in the intergenerational, or parent-child, influence literature stream (e.g., Moore et al. 2002) and extends to consider simultaneous intragenerational, or sibling, influences on consumer behavior.

\section{FAMILY INFLUENCES ON INNOVATIVENESS}

Our conceptual model argues that both parents and siblings can influence a person's innovativeness and that in- 
novativeness will lead to trial of more innovative products and services. In building our hypotheses, we consider current research on consumer-oriented perspectives of innovation adoption, parental influence, and sibling influence.

\section{Innovativeness and Innovative Behavior}

As we are interested in testing both intragenerational and intergenerational influences simultaneously, it is necessary to study a domain in which it is possible that both interand intragenerational influence occurs. One such domain is consumer innovativeness, the tendency to want to embrace change and try new behaviors or products.

Consumer innovativeness, as a phenomenon or personality construct, has interested researchers for some time (e.g., Hirschman 1980; Manning, Bearden, and Madden 1995; Midgely and Dowling 1978). Recent conceptualizations emphasize that innovativeness comprises dual dimensions, both cognitive and sensory (Venkatraman and Price 1990). From a sensory perspective, consumers might be innovative due to higher than average optimal stimulation level (OSL) preferences, regulated through variety-seeking behaviors (Menon and Kahn 1995) or novel products exploration (Raju 1980). Cognitively, innovativeness may reveal itself in increased information gathering or product involvement (Goldsmith 1983; Raju 1980). Although measures of innovativeness have not always been reliable indicators of innovative behavior (Steenkamp and Baumgartner 1992), the prediction of innovative behavior is significantly improved by the explicit consideration of both cognitive and sensory dimensions (Wood and Swait 2002).

Thus, following Wood and Swait (2002), we measure the underlying bases for innovativeness using two subscales: the need for cognition $\left(N_{\text {cog }}\right)$ and the need for change $\left(N_{\text {chg }}\right)$. The need for cognition has been defined as the tendency to think or enjoy thinking per se (Cacioppo and Petty 1982) and is a well-established and often used measure in fields such as attitude and persuasion. The need for change $\left(N_{\text {chg }}\right)$ has been defined as the tendency to value or embrace change for its own sake and is a measure developed from several items of sensory-oriented innovativeness (Price and Ridgeway 1983; Raju 1980; Wood and Swait 2002; Zuckerman 1979).

\section{Parental Influence}

Extant consumer research on families focuses primarily on the dyad between a parent and one child. Researchers have studied this family influence under the aegis of socialization (e.g., Moschis 1987; Ward 1974) or, more recently, as intergenerational influence, originally conceived of as a result of communication patterns and frequency within the family (Carlson and Grossbart 1988). Both the classic approach to family influence and more recent research trends offer insights into parent/sibling influence.

The effect of the parent in the socialization of offspring has been shown to affect many key consumer behaviors, including brand preference and loyalty, information search, reliance on mass media, and price sensitivity (Childers and Rao 1992; Moschis 1987; Ward 1974). The underlying theme of traditional family socialization research is parents transmit values and attitudes as well as purchasing habits, brand preferences, and so on to children. This socialization approach assumes that children learn through modeling and other social learning tenets (Moschis 1987). That is, children learn consumer behaviors because their parents directly teach them and/or because they learn vicariously through observation of their parents' behaviors. A related approach examines general parenting style and its purported influence on child behavior (e.g., Carlson and Grossbart 1988).

Intergenerational influence research has evolved from this relatively straightforward socialization approach to focus on how the child's perception of the home affects his or her attitudes (Moore-Shay and Berchmans 1996). This more recent intergenerational influence approach to studying family influence, based on balance theory applied in a communications vein, suggests that increased communication within families leads to more learning (Moore-Shay and Lutz 1988) and incorporates both parent-to-child and childto-parent flows of influence. We adopt the recent definition offered by Moore and her colleagues that intergenerational influence is "the within family transmission of information, beliefs, and resources from one generation to the next" (Moore et al. 2002, p. 17). A summary of findings across intergenerational studies suggests that buying styles and skills are often shared intergenerationally. As Moore et al. (2002) review, research to date has shown that family influences help children create their identities. Researchers contend that this influence occurs via both observational learning and communication and that this intergenerational influence continues to influence adult children (Moore et al. 2002; Whitbeck and Gecas 1988).

Most, if not all of the research reviewed above argues theoretically that it is the children's perception of their parent that influences the child. This perception may or may not be accurate, but the child's perception will influence them more than the true consumer behaviors of the parents. So, although we did collect direct measures of the parent's (and sibling's) innovativeness, we believe it makes more sense to use one's perceptions of one's parents and one's sibling. Given a significant body of evidence for parental influence, we propose:

H1: There will be an intergenerational influence on innovativeness. The more innovative a parent is perceived to be by his or her son or daughter, the more innovative the son or daughter will be.

\section{Sibling Influence}

Siblings can be important role models for each other and in many cases could act as a relevant peer group for comparison and modeling. Especially in adolescence, when peer comparisons are especially salient (Pechmann and Knight 2002) siblings are likely to be a strong reference group. 
Thus, in some domains, the siblings in the home may socialize each other more than the parents do (one may think of music preferences, for example). In these instances, the influence can thus be thought of as intragenerational, and siblings become an important reference group influencing behavior (Bearden and Etzel 1982). Thus, some readers with children may note "my younger child copies everything the older one does," and, hence, these readers may argue that sibling influence should be strong.

Indeed, Hoffman (1991) points out that siblings are in fact sometimes similar, showing that the average intraclass correlation between siblings is usually greater than zero and in some domains (e.g., hobbies) is significant, although not strong. Researchers have demonstrated that attitudes and interests show somewhat more similarity among siblings than more general personality measures (Hoffman 1991; Loehlin, Willerman, and Horn 1988).

However, many readers, if they have siblings, may be mentally arguing "but I am nothing like my brother/sister." This observation is consonant with recent work outside consumer research, in both behavioral genetics and family socialization. Research over the last 2 decades in these fields has documented that siblings are surprisingly different from one another (e.g., Hoffman 1991; Schacter et al. 1976). This stream of research argues that although there are genetic reasons for siblings to be somewhat different, a purely genetic basis does not account for the degree of variation seen within families on sibling personality types, and sibling differences outweigh similarities for most psychological traits (Dunn and Plomin 1990; Plomin and Daniels 1987; Scarr and Grajek 1982). Behavioral geneticists state that the differences not due to heredity are environmental; that is, families create some of the differences we observe in siblings. Parents may create differences between their children not only because they pass on different genes but also because they create different environments for each child in the family (Harris 1995; Hoffman 1991; Scarr and Grajek 1982). The most straightforward example of this different environment is birth order. A child born with an older sibling faces a different environment than does a child born first, with no older sibling.

From the identification of the factors that can create differences between siblings has blossomed the literature on "non-shared environments" (Dunn and Plomin 1990; Graham-Bermann 1991; Hoffman 1991). The simple yet powerful reconceptualization in this research stream is that family influences operate differently for different children within the same family. Even when children experience the same objective family environment or event (e.g., a mother losing her job), differences in age when the event occurs and genetics (as well as other objective differences) lead children to subjectively experience this environment or event differently (Hoffman 1991). Different subjective experiences may be exacerbated by birth order rank (Dunn and Plomin 1990).

Other researchers have explored how and why children and parents appear to actively create, perhaps unconsciously, different environments within the family for each sibling
(Ross and Milgram 1982; Schachter and Stone 1987). Schachter and Stone's work on "sibling deidentification" finds that siblings define themselves as different and so do their parents. By the time their first two children have reached 6 years of age, mothers begin to see the children as completely opposite in personalities and aptitudes, and that opinion rarely changes over time (Schachter and Stone 1987). These researchers also find that siblings are about twice as likely to report being different as they are to report being alike (see also Graham-Bermann 1991).

Thus, siblings themselves try to accentuate their differences (Ross and Milgram 1982; Schachter and Stone 1987). Festinger's social comparison theory (Festinger 1954) was used by Schachter and Stone (1987) to explain why siblings try to appear to be, and often are, so different from one another. That is, if siblings find the constant comparison with the other sibling painful, they will attempt to make the other sibling a nonrelevant comparison. Ross and Milgram (1982) go further, claiming that sibling rivalry can be generated both by the self, as outlined above, and by parental behavior, as when parents assign roles or engage in favoritism. Tesser's (1988) self-evaluation maintenance theory continues in this vein, contending that siblings will develop their own niche areas of expertise that create a unique sense of identity.

So we have a situation where, on the one hand, siblings can and do act as a relevant peer group for each other and may socialize each other to similar attitudes and behaviors. On the other hand, although siblings share at least some genetically derived similarity and share some of the same family environment, they also experience this environment quite differently, and they may try to cultivate differences, particularly as adolescents and adults. Family influences may work to differentiate siblings, not make them similar. Further, siblings themselves often attempt to maximize this contrast. This leads to two competing hypotheses concerning innovativeness:

H2a: There will be a positive intragenerational influence on innovativeness and innovative behavior. The more innovative a person perceives his or her sibling to be, the more innovative he or she will be.

H2b: There will be a negative intragenerational influence on innovativeness and innovative behavior. The more innovative a person perceives his or her sibling to be, the less innovative he or she will be.

The natural extension of these hypotheses investigates the relative strength of family influence. Will parental influence or sibling influence have a greater impact on a person's innovativeness? Because of the dual nature of innovativeness, created by both need for cognition and need for change, both parental and sibling influence is possible. First, parents may set the tone for, and perhaps influence at a genetic level, appropriate levels of involvement and cognition required for 
FIGURE 1

CONCEPTUAL MODEL: FAMILY INFLUENCE ON INNOVATIVE BEHAVIOR

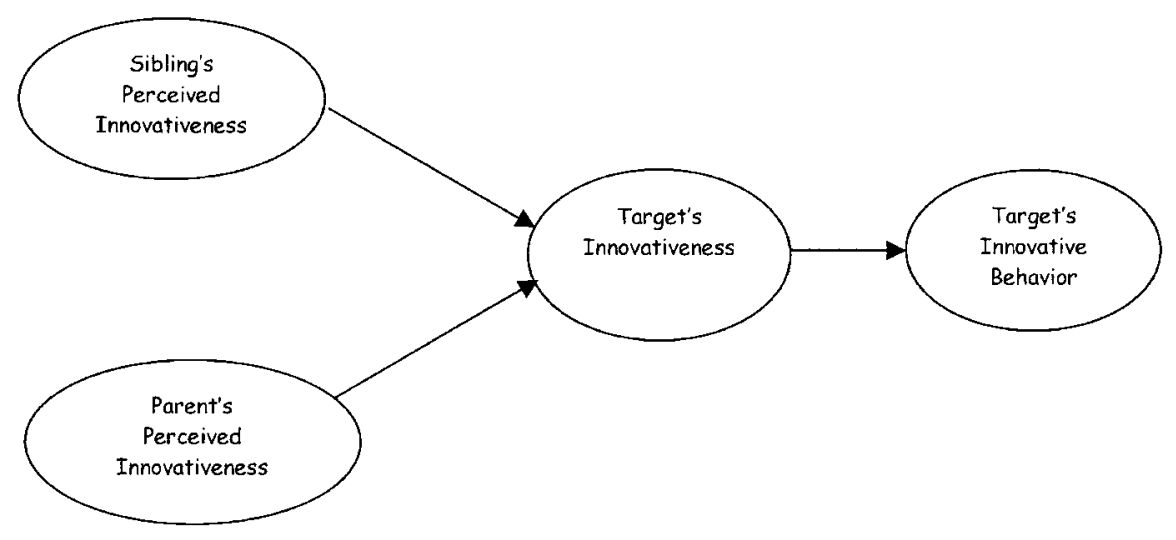

consumption decisions. Parents may also act as models for their children by their own information-seeking and decisionmaking behaviors. Second, siblings may influence norms of desired stimulation or expectations of being on the cutting edge. A sibling, as an age-appropriate reference point, may demonstrate a norm for the acceptance or avoidance of traditional, status quo products. However, as we have noted, a person may attempt to position his or her self-schema away from that of a sibling in a process of deidentification. This deidentification is not likely with parents, because they are not a relevant comparison-psychologically it may be more important for a child to prove he or she is different from a sibling (Ross and Milgram 1982; Schachter and Stone 1987; Tesser 1988). Therefore, because the potential for parental influence is relatively unconflicted, while the potential for sibling influence is rendered ambiguous by identity issues, we propose that parental influence will be stronger on an individual's innovativeness than sibling influence. Thus:

H3: The influence of a parent's perceived innovativeness and innovative behavior on his or her adult child's innovativeness will be greater than the influence of a sibling's perceived innovativeness and behavior on the same adult child's behavior. That is, intergenerational influence will be greater than intragenerational influence on innovativeness.

Finally, it is important to demonstrate that innovativeness is predictive of innovative behavior. It has been previously noted that past attempts to predict product usage behavior based on the measured personality construct have not always been successful (Steenkamp and Baumgartner 1992). Therefore, to validate the significance of intergenerational and intragenerational influence within this domain, we hypothesize:

H4: Innovativeness will be positively associated with trial of innovative products.

The conceptual framework underlying our four key hy- potheses can be seen in figure 1 . We now turn to a description of the data collection and triadic analysis used to test these hypotheses.

\section{DATA COLLECTION}

We recruited undergraduate students at a large state university to complete a survey and provide the name and mailing address of an adult sibling (over 18 years of age) and a parent. The students completed their surveys in the lab, and then we mailed the sibling and parent surveys, with a prepaid phone card included as an incentive. Four hundred and eighty-six surveys were distributed and 469 (including the surveys completed by the students in the lab) were returned, for an initial response rate of $96.5 \%$. However, of the 469 returned, we could not use 30 surveys due to large amounts of missing data. Due to the triadic nature of the study, we could not use 28 of the original surveys because they belonged to a family with nonreturned or incomplete surveys. Thus, the final number of returned and usable surveys was 411, for a final response rate of $84.6 \%$, and 137 families with complete data from all three family members.

\section{Survey Instrument}

The survey instrument consisted of several distinct parts. The first page contained scales to measure the respondent's need for change and need for cognition. Next, we asked respondents to predict the need for change and need for cognition of the other two family members participating in the study (an adult sibling and a parent). This coorientation-based measurement method has been used successfully in consumer research (e.g., Moore-Shay and Berchmans 1996). Although respondents will likely make implicit comparisons between themselves and other family members, research on impression management suggests that this is not a problem when assessing family agreement (Hunsley et al. 1996). The survey then included behavioral measures ("have you used . . .?") for a variety of innovations, ranging from moderate to dis- 
TABLE 1

SCALE ITEMS AND RELIABILITIES

\begin{tabular}{|c|c|}
\hline Scale items & $\alpha$ \\
\hline Need for cognition: & $\begin{array}{l}\text { Average for self ratings is } .73 \\
\text { Average for rating others in triad is } .80\end{array}$ \\
\hline I would rather do something that requires little thought than something & \\
\hline \multicolumn{2}{|l|}{$\begin{array}{l}\text { I'll have to think in depth about something. } \\
\text { lo is a likely chance }\end{array}$} \\
\hline \multicolumn{2}{|l|}{ I only think as hard as I have to. } \\
\hline \multicolumn{2}{|l|}{$\begin{array}{l}\text { The idea of relying on thought to get my way to the top does not ap- } \\
\text { peal to me }\end{array}$} \\
\hline \multicolumn{2}{|l|}{ The notion of thinking abstractly is not appealing to me } \\
\hline Need for change: & $\begin{array}{l}\text { Average for self ratings is } .65 \\
\text { Average for rating others in triad is } .75\end{array}$ \\
\hline \multicolumn{2}{|l|}{$\begin{array}{l}\text { When I see a new or different brand on the shelf, I often pick it up } \\
\text { just to see what it is like. }\end{array}$} \\
\hline \multicolumn{2}{|l|}{ I like introducing new brands and products to my friends. } \\
\hline \multicolumn{2}{|l|}{$\begin{array}{l}\text { I enjoy taking chances in buying unfamiliar brands just to get some } \\
\text { variety in my purchase. }\end{array}$} \\
\hline \multicolumn{2}{|l|}{$\begin{array}{l}\text { I often read the information on the packages of products just out of } \\
\text { curiosity. }\end{array}$} \\
\hline \multicolumn{2}{|l|}{ I get bored with buying the same brands even if they are good. } \\
\hline $\begin{array}{l}\text { I shop around a lot for my clothes just to find out more about the lat- } \\
\text { est styles. }\end{array}$ & \\
\hline
\end{tabular}

continuous innovations in a variety of price ranges. The survey ended with basic demographics (age, gender, number of siblings, birth order, and education). Some of the items and scales were adapted from previous studies, whereas we constructed several indices, as outlined below.

\section{Measures}

Need for Cognition. The need for cognition is a wellknown measure of an individual's tendency to enjoy thinking per se (Cacioppo and Petty 1982). We use a five-item version of the $N_{\text {cog }}$ scale (like in Wood and Swait 2002) that showed adequate reliability (see table 1 ).

Need for Change. The need for change is the extent to which individuals value novelty and innovation and how comfortable one is with change (Wood and Swait 2002). This six-item scale was originally created drawing on items from the Sensation-Seeking scale (Zuckerman 1979), the Exploratory Tendencies in Consumer Behavior scale (Raju 1980), and the Use Innovativeness scale (Price and Ridgeway 1983). This scale had somewhat lower reliabilities than the $N_{\text {cog }}$ scale (see table 1 ).

Innovative Behavior Index. As is conventional in the prior research on innovative behavior (e.g., Foxall 1995; Im, Bayus, and Mason 2003) we use a measure of innovative behavior operationalized as the number of products used from a list of innovative products. We assessed trial of new products and distribution channels with a yes/no "have you used . . ." format for eight innovations: using the Internet at home, a shower spray that cleans without scrubbing, cellular phone, whitening toothpaste, ginkgo/echinacea, stain- removing "wipes," making a purchase over the Internet, and an antibacterial "waterless" hand cleaner. It was important to use innovative behaviors that would not be materially affected by differences in parent and child incomes (e.g., high definition television). Each innovation tried was assigned a one, and no trial was assigned a zero. We summed the behaviors to create an index. The products varied across both degree of innovation and expense, ranging from whitening toothpaste to cell phones (note that at the time of the data collection, these products could still be considered innovations).

\section{DATA ANALYSIS}

\section{Sample Characteristics and Control Variables}

To differentiate the three members of the family triad clearly, we will use "target" to refer to the undergraduate student initially contacted and "sibling" to refer to the adult, recruited sibling. Of the targets responding, 39\% were male, and $61 \%$ were female. Of the siblings, $42 \%$ were male and $58 \%$ were female. Twenty-two percent of the parents were fathers, and $78 \%$ were mothers. In terms of the sibling pairs, $37 \%$ were sisters, $16 \%$ were brothers, and $47 \%$ were mixed gender. In terms of the target and parent pairs, 49\% (68 families) were mothers and daughters, 12\% (15 families) were fathers and sons, and $39 \%$ were mixed gender. Of these mixed gender pairs (54 families), $70 \%$ (38 families) were mothers and sons, and 30\% (16 families) were fathers and daughters.

The targets ranged from firstborn to seventh born, with the modal answer, and the median, being the second born. Thirty-two percent were firstborn, $46 \%$ were second born. 
TABLE 2

PATH COEFFICIENTS IN THE STRUCTURAL MODEL

\begin{tabular}{lc}
\hline \hline Path & Coefficient \\
\hline $\begin{array}{l}\text { Perceived innovativeness of sibling } \\
\quad-\text { innovativeness of target }\end{array}$ & .250 \\
$\begin{array}{l}\text { Perceived innovativeness of parent - } \\
\quad \text { innovativeness of target }\end{array}$ & .408 \\
Birth order - innovativeness of target & .169 \\
Innovativeness of target - target in- & \\
$\quad$ novative trial behavior & .213 \\
$R^{2}$ (Innovativeness of target) & .286 \\
$R^{2}$ (Target innovative trial behavior) & .045 \\
\hline
\end{tabular}

NOTE.-All standardized path coefficients are significant at $p<.05$.

The average number of children in the family was three, with a standard deviation of 1.34 (minimum two, maximum 12). The average age of the target was 21 , while the average age of the sibling responding was 23 . This age difference is significant $(p<.0001)$. Over all the families (regardless of who is older), the mean age difference between the siblings is 4 years. When we use the 82 families where the sibling respondent is older ( $60 \%$ of the families) the mean age difference is 5 years. In the analysis that follows, the age of the target, as well as the age difference between the target and the sibling, were both used as control variables; neither was significant, and both variables were dropped from further consideration. As with age, the number of children in the family was also added to the analysis as a control variable; it was not significant, and was dropped from the analysis for parsimony.

In keeping with the family socialization literature, we recognize that birth order is likely to play a part in family influence (Sulloway 1996). Firstborn children are more likely to be conformists and are more likely to echo their parents' values, while later born children are likely to be unconventional and innovative (Sulloway 1996). The presence of an older child could give younger children a baseline behavior to "rebel" against, in part due to sibling deidentification. Birth order is a significant covariate that we control for in our model, as it reduces the error variance by helping explain part of the variation in the dependent variable of innovativeness.

\section{Analysis Approach}

Our structural model is depicted as our conceptual model (fig. 1), with birth order included as a covariate. ${ }^{1}$ The measurement model consists of formative indicators for each construct as follows: both sibling's perceived innovativeness and parent's perceived innovativeness have three indicators each. The first two indicators are the target's perceptions about each family member's need for cognition and their perceptions about the family member's need for change (re-

${ }^{1}$ This structural equations model is fit via partial least squares rather than Lisrel due to our relatively small sample size (Hulland 1998; Wold 1982). call that the survey asked each member of the family for these predictions/perceptions about the other two family members). The final indicator for these latent constructs is each family member's actual innovative behavior, measured by their score on the innovative behavior index. Thus, the target's perceptions of their parent and sibling are based on perceptions about their personalities, as well as observations of their behavior. Target's innovativeness is measured with two indicators, need for change and need for cognition, and target's innovative behavior is the target's score on the innovative behavior index. The covariate birth order is a measured variable.

\section{RESULTS}

On a possible zero to eight scale, the minimum score on the innovative behavior index across all groups (targets, siblings, parents) was one (only tried one innovation) and the maximum score was eight. There was a significant difference between the number of innovations the target had tried $(M=4.7, \mathrm{SD}=1.61)$ and how many the sibling had tried $(M=4.3, \mathrm{SD}=1.46, p=.04)$ and between the target and the parent $(M=4.3, \mathrm{SD}=1.57, p=.03)$. The sibling and the parent are not significantly different on their trial of innovative products $(p=.961)$. The target exhibits more innovative behavior than either the sibling or the parent.

All of the paths in our main structural model are significant (see table 2). However, in the measurement model, the weights from the $N_{\text {chg }}$ indicators to each latent construct are not significant (recall its low reliability).

Our model explains the innovativeness of the target fairly well, with about $29 \%$ of the variance in innovativeness explained by intergenerational and intragenerational influences and birth order. We note that birth order, which we included as a covariate, did have a significant impact on innovativeness. The later one is born (and in our sample this tends to mean being second born vs. firstborn) the more innovative one tends to be, consonant with some family socialization research (Sulloway 1996).

Supporting hypothesis 1 , the data shows a significant influence of the parent's perceived innovativeness and behavior on the target's innovativeness (see table 2). The influence of the sibling's perceived innovativeness on the target's innovativeness is also positive and significant, supporting hypothesis $2 \mathrm{a}$ and not supporting the competing hypothesis $2 \mathrm{~b}$. The target's perceptions of the parent, the sibling, and the target's birth order together account for $28.6 \%$ of the total variance in target innovativeness.

To test hypothesis 3 , we must assess the relative influence of each variable to the target's innovativeness. Continuing to include birth order as a covariate, we can compare each of the exogenous variables' importance (sibling's influence, parent's influence, and birth order) by squaring each path coefficient and dividing by the sum of all of the squared path coefficients ( $25.8 \%$ vs. the total $R^{2}$ of $28.6 \%$ ) to roughly assess what each variable contributes to the variance explained by all three. This procedure eliminates any variance 
attributed to multicollinearity, which is not a serious problem in our data. This analysis shows that the parent is far more of an influence on the target than is the sibling, supporting hypothesis 3 . The parent's influence explains $65 \%$ of the variance, sibling influence accounts for $24 \%$ of the variance, and birth order accounts for only $11 \%$ of the variance explained by the three exogenous variables together.

Our data also support hypothesis 4, which states that innovativeness will lead to innovative behavior. However, the $R^{2}$ for this relationship is a modest $4.5 \%$. That is, ultimate behavior is explained less well by our model. However, this effect, although modest, is still demonstrated at a meaningful level. As has been noted, strong innovative behavior effects have been difficult to capture through personality constructs (Steenkamp and Baumgartner 1992).

\section{DISCUSSION}

As Roedder John (1999) points out, important gaps exist in our understanding of family and social environment influence in consumer socialization. Our research attempts to fill some of these gaps by disaggregating the concept of family influence into two constituent parts, parental and sibling influences, and examining these in the context of innovative consumer behavior.

We find that innovative behavior is influenced both intergenerationally and intragenerationally, but that intergenerational influences are dominant. In particular, we show that adult children's perceptions of their parent's innovativeness influence their own innovativeness. We should note that our conclusions run counter to a controversial theory of family socialization in psychology (Harris 1995). Harris's contention is that children are different because they have different peer groups and experiences outside the home and family, which make them different. Parents have a small genetic influence (creating similarities between siblings), but parental style and socialization make no difference in the behavior of the individual as an adult. In essence, Harris argues that if children remained in their neighborhoods, schools, and teams (i.e., in all their peer group relationships) they would develop into the same people even if all the parents were randomly switched. We present data in this study that run contrary to this theory, demonstrating a strong and unique association between children's perception of their parents' innovativeness and the children's innovativeness.

One limitation of this research is our necessary reliance on a moderately narrow conceptualization of innovativeness. In the long history of scale development and other attempts to capture innovativeness, several researchers have advocated a more focused or specialized perspective (such as Raju's [1980] focus on exploratory behaviors). However, other researchers have identified a diverse set of traits and behaviors that may contribute to innovative tendencies (e.g., Hirschman 1980; Midgely and Dowling 1978). Due to the nature of our empirical analysis, we were limited in the number of dimensions we could meaningfully consider. We found the dual component framework of affective and cognitive subparts (Venkatraman and Price 1990; Wood and
Swait 2002) effective. It provided a moderate level of conceptual complexity, considering both sensory and information-processing elements of innovativeness, that has proved empirically viable in predicting innovative behavior (Wood and Swait 2002) as many more broad conceptualizations have not (see Steenkamp and Baumgartner [1992] for a thorough discussion). However, this is not to suggest that a more broadly conceived picture of innovativeness is not worthwhile. Different analytical methods will be required to elucidate socialization effects given a broad conceptualization of innovativeness. It is our hope that the findings here encourage future researchers to seek out and engage in these methods.

A second opportunity lies in more fully explaining sibling deidentification as a potential moderator of influence. We present hypothesis 2 as competing alternatives. In motivating hypothesis $2 \mathrm{~b}$, we suggested that siblings may actively try to be different from one another and thus negatively influence the other's behavior. Our results did not show this. Yet the possibility exists that sibling deidentification affects the relative strength of sibling versus parental influence (hypothesis 3). Similarly, if sibling deidentification does not exist in a family triad, then parent influence may operate in two ways: (1) directly from parent to child and (2) indirectly through the parent's influence on a sibling. However, because we did not measure sibling deidentification, we cannot speak conclusively to this issue. There is some evidence in our data that dispels indirect parental influence in that the combined influence of the sibling, which would include any indirect parental influence, is not greater than the parent's influence alone. Notwithstanding this, one goal of future research should be to partial out the (potentially interactive) influence of sibling/parent socialization, perhaps by investigating family triads with differing levels of measured sibling deidentification.

Finally, consumer socialization research would benefit from further study on factors that moderate sibling influence. We can imagine two categories that may describe potential moderators, family characteristics and individual traits. Family characteristics may include such variables as level of family closeness, conflict, economic status, number of children in the household at a given time, and parents' explicit use of siblings as points of comparison or judgment. Individual traits may include the child's learning style, independence, competitiveness, and self-efficacy beliefs. These variables, both family and individual based, offer many fruitful avenues for future research.

[Dawn Iacobucci served as editor for this article.]

\section{REFERENCES}

Bearden, William O. and Michael J. Etzel (1982), "Reference Group Influence on Product and Brand Purchase Decisions," Journal of Consumer Research, 9 (September), 183-94.

Cacioppo, John T. and Richard E. Petty (1982), "The Need for Cognition," Journal of Personality and Social Psychology, 42 (1), 116-31. 
Carlson, Les and Sanford Grossbart (1988), "Parental Style and Consumer Socialization of Children," Journal of Consumer Research, 15 (1), 77-94.

Childers, Terry L. and Akshay R. Rao (1992), “The Influence of Familial and Peer-Based Reference Groups on Consumer Decisions," Journal of Consumer Research, 19 (September), 198-211.

Dunn, Judy and Robert Plomin (1990), Separate Lives, New York: Basic.

Festinger, Leon (1954), "A Theory of Social Comparison Processes," Human Relations, 7, 117-40.

Foxall, Gordon R. (1995), "Cognitive Styles of Consumer Initiators," Technovation, 15 (5), 269-88.

Goldsmith, Ronald E. (1983), "Psychographics and New Product Adoption: An Exploratory Study," Perceptual and Motor Skills, 57, 1071-76.

Graham-Bermann, Sandra A. (1991), "Siblings in Dyads: Relationships among Perceptions and Behavior," Journal of Genetic Psychology, 152 (2), 207-16.

Harris, Judith Rich (1995), "Where Is the Child's Environment? A Group Socialization Theory of Development," Psychological Review, 102 (3), 458-89.

Hirschman, Elizabeth (1980), "Innovativeness, Novelty Seeking, and Consumer Change," Journal of Consumer Research, 7 (December), 283-95.

Hoffman, Lois Wladis (1991), "The Influence of the Family Environment on Personality: Accounting for Sibling Differences," Psychological Bulletin, 110 (2), 187-203.

Hulland, John (1998), "Use of Partial Least Squares in Strategic Management Research," Comportamento Organizacional E Gestao, 4 (1), 181-202.

Hunsley, John, Diana Vito, Celine Pinsent, Susan James, and Monique Lefebvre (1996), “Are Self-Report Measures of Dyadic Relationships Influenced by Impression Management Biases?" Journal of Family Psychology, 10 (3), 322-30.

Im, Subim, Barry L. Bayus, and Charlotte H. Mason (2003), “An Empirical Study of Innate Consumer Innovativeness, Personal Characteristics, and New-Product Adoption Behavior," Journal of the Academy of Marketing Science, 31 (1), 61-73.

Loehlin, John C., Lee Willerman, and Joseph M. Horn (1988), "Human Behavior Genetics," Annual Review of Psychology, 39, 101-33.

Manning, Kenneth C., William O. Bearden, and Thomas J. Madden (1995), "Consumer Innovativeness and the Adoption Process," Journal of Consumer Psychology, 4 (4), 329-46.

Menon, Satya and Barbara E. Kahn (1995), "The Impact of Context on Variety Seeking in Product Choices," Journal of Consumer Research, 22 (December), 285-95.

Midgely, David F. and Grahame R. Dowling (1978), "Innovativeness: The Concept and Measurement," Journal of Consumer Research, 4 (March), 229-42.

Moore, Elizabeth S., William L. Wilkie, and Richard J. Lutz (2002), "Passing the Torch: Intergenerational Influence as a Source of Brand Equity," Journal of Marketing, 66 (April), 17-37.

Moore-Shay, Elizabeth S. and Britto M. Berchmans (1996), "The Role of the Family Environment in the Development of Shared Consumption Values: An Intergenerational Study," in Advances in Consumer Research, Vol. 23, ed. Kim P. Corfman and John G. Lynch, Jr., Provo, UT: Association for Consumer Research, 484-90.

Moore-Shay, Elizabeth S. and Richard J. Lutz (1988), "Intergenerational Influences in the Formation of Consumer Attitudes and Beliefs about the Marketplace: Mothers and Daughters," in Advances in Consumer Research, Vol. 15, ed. Michael J. Houston, Provo, UT: Association for Consumer Research, 461-67.

Moreau, C. Page, Donald R. Lehmann, and Arthur B. Markman (2001), "Entrenched Knowledge Structures and Consumer Response to New Products," Journal of Marketing Research, 38 (February), 14-29.

Moschis, George P. (1987), Consumer Socialization: A Life-Cycle Perspective, Lexington, MA: Lexington.

Pechmann, Cornelia and Susan J. Knight (2002), “An Experimental Investigation of the Joint Effects of Advertising and Peers on Adolescents' Beliefs and Intentions about Cigarette Consumption," Journal of Consumer Research, 29 (June), 5-19.

Plomin, Robert and Daniels, Denise. (1987), "Why Are Children in the Same Family so Different from Each Other?" Behavioral and Brain Sciences, 10 (March), 1-16.

Price, Linda L. and Nancy M. Ridgeway (1983), "Development of a Scale to Measure Use Innovativeness," in Advances in Consumer Research, Vol. 10, ed. Richard P. Bagozzi and Alice M. Tybout, Provo, UT: Association of Consumer Research.

Raju, P. S. (1980), "Optimum Stimulation Level: Its Relationship to Personality, Demographics, and Exploratory Behavior," Journal of Consumer Research, 7 (December), 272-82.

Roedder John, Deborah (1999), "Consumer Socialization of Children: A Retrospective Look at Twenty-Five Years of Research," Journal of Consumer Research, 26 (December), 183-213.

Rogers, Everett M. (1995), Diffusion of Innovations, 4th ed., New York: Free Press.

Ross, Helgola G. and Joel I. Milgram (1982), "Important Variables in Adult Sibling Relationships: A Qualitative Study," in Sibling Relationships, ed. Michael E. Lamb and Brian SuttonSmith, Hillsdale, NJ: Erlbaum, 225-50.

Scarr, Sandra and Susan Grajek (1982), "Similarities and Differences among Siblings," in Sibling Relationships, ed. Michael E. Lamb and Brian Sutton-Smith, Hillsdale, NJ: Erlbaum, 357-81.

Schacter, Francis Fuchs, Ellen Shore, Susan Feldman-Rotman, Ruth E. Marquis, and Susan Campbell (1976), "Sibling Deidentification," Developmental Psychology, 12 (5), 418-27.

Schacter, Francis Fuchs and Richard K. Stone (1987), "Comparing and Contrasting Siblings: Defining the Self," Journal of Children in Contemporary Society, 19 (3-4), 55-75.

Steenkamp, Jan-Benedict E. M. and Hans Baumgartner (1992), "The Role of Optimum Stimulation Level in Exploratory Consumer Behavior," Journal of Consumer Research, 19 (December), 434-48.

Sulloway, Frank J. (1996) Born to Rebel: Birth Order, Family Dynamics, and Creative Lives, New York: Pantheon.

Tesser, Abraham (1988), "Toward a Self-Evaluation Maintenance Model of Social Behavior," in Advances in Experimental Social Psychology, Vol. 21, ed. L. Berkowitz, San Diego, CA: Academic Press, 181-227.

Ward, Scott (1974), "Consumer Socialization," Journal of Consumer Research, 1 (September), 1-14.

Whitbeck, Les B. and Viktor Gecas (1988), "Value Attributions and Value Transmission between Parents and Children," Journal of Marriage and the Family, 50 (August), 829-40.

Wold, Herman (1982), "Systems under Indirect Observation Using PLS," in A Second Generation of Multivariate Analysis, Vol. 1, Methods, ed. Claes Fornell, New York: Praeger, 325-47.

Wood, Stacy L. and John G. Lynch, Jr. (2002). "Prior Knowledge 
and Complacency in New Product Learning," Journal of Consumer Research, 29 (December), 416-26.

Wood, Stacy L. and Joffre Swait (2002), "Psychological Indicators of Innovation Adoption: Cross-Classification Based on Need for Cognition and Need for Change," Journal of Consumer Psychology, 12 (1), 1-13.
Venkatraman, Meera P., and Linda L. Price (1990), "Differentiating between Cognitive and Sensory Innovativeness: Concepts, Measurement, and Implications," Journal of Business Research, 20 (June), 293-315.

Zuckerman, Marvin (1979), Sensation Seeking: Beyond the Optimal Level of Arousal, Hillsdale, NJ: Erlbaum. 
Copyright of Journal of Consumer Research is the property of Journal of Consumer Research, Inc. and its content may not be copied or emailed to multiple sites or posted to a listserv without the copyright holder's express written permission. However, users may print, download, or email articles for individual use. 